\title{
Effect of Desmopressin in Reducing Bleeding after Cardiac Surgery in Patients Receiving Anti-Platelet Agents
}

\begin{abstract}
Kamran Shadvar ${ }^{1}$, Fatemeh Azizi², Ata Mahmoodpoor ${ }^{3}$, Hadi Hamishehkar ${ }^{4}$, Bahman Naghipour ${ }^{3 *}$, Reza Movassaghi ${ }^{3}$
\end{abstract}

1. Cardiovascular Research Center, Tabriz University of Medical Sciences, Tabriz, Iran

2. Faculty of Medicine, Tabriz University of Medical Sciences, Tabriz, Iran

3. Department of Anesthesiology and Intensive Care, Tabriz University of Medical Sciences, Tabriz, Iran

4. Applied Drug Research Center, Tabriz University of Medical Sciences, Tabriz, Iran

\begin{abstract}
Background: Severe bleeding is an important cause of morbidity and mortality in cardiac surgery using the cardiopulmonary bypass (CPB) pump. Desmopressin, a synthetic analogue of vasopressin, is used to prevent postoperative bleeding in patients with renal insufficiency. The aim of the present study was to evaluate the effect of desmopressin in reducing blood loss after cardiac surgery in patients receiving antiplatelet drugs. Methods: In this prospective clinical trial, 40 patients undergoing coronary artery bypass grafting (CABG) surgery with $\mathrm{CPB}$, aged over 18 years, and on antiplatelet therapy for a week before surgery were divided in two groups. Case and control groups received nasal desmopressin spray and nasal normal saline spray, respectively. Patient vital signs, blood loss, administration of blood products, prescription drugs to improve the coagulation status, serum and whole intake and output of patients, need for a second surgery to control the bleeding, remaining sternum open, mortality due to bleeding, duration of intensive care unit (ICU) stay and mechanical ventilation were recorded. Results: In the case and control groups there were no differences in duration of operation, mechanical ventilation and length of ICU stay. There was no significant difference in terms of postoperative bleeding and intake of blood products between two groups $(P>0.05)$. Reoperation due to bleeding in the case and control groups was observed in $3(15 \%)$, and $1(5 \%)$ patient(s), respectively $(P=0.3)$. Conclusion: Desmopressin has no significant effect on reducing the amount of bleeding after cardiac surgery in patients receiving anti-platelet agents.
\end{abstract}

Keywords: CABG; cardio pulmonary bypass pump; hemorrhage; desmopressin

\section{Introduction}

In recent years, there has been a significant progress in cardiac surgery and mortality rate has been reduced due to improvement in anesthetic and surgical techniques and patient care either in operating room or in later stages of the operation. Cardio pulmonary bypass (CPB) is an integral part of the majority of cardiac surgeries, and it has made a huge change in cardiac surgery since its invention. Despite benefits of CPB in patients undergoing heart surgery, it is also associated with

\section{Corresponding author:}

Bahman Naghipour

Department of Anesthesiology, Tabriz University of Medical Sciences, Tabriz, Iran

E-mail: b_naghipour@yahoo.co.uk Phone: +989143019621

Receive date: 2016-05-01| Accept date: 2016-06-25| Publish date: 2016-07-28

DOI: 10.7575/aiac.abcmed.16.04.03.01

\section{A. I}


neurologic, pulmonary, metabolic and hemostatic side effects (1-4).

Although incomplete hemostasis is the most common cause of bleeding after heart surgery, clotting problems caused by CPB can be involved in creating microvascular bleeding (5). Reducing the number and function of platelets can occur following $\mathrm{CPB}$, which is because of the blood contact with oxygenator, and $\mathrm{CPB}$ circuit, hemodilution, activation, degranulation, aggregation and destruction of platelets caused by CPB (6-7).

Desmopressin (1-desamino-8-D-arginine vasopressin) is a synthetic vasopressin analogue used in patients with diabetes insipidus as well as in patients with hemophilia A and Von Willebrand disease $(8,9)$. This drug is used to prevent postoperative bleeding in patients with renal failure and improves platelet function and increases factor VIII and Von Willebrand factor (9-15).

Bleeding after cardiac surgery is associated with increased mortality, keeping the sternum open, risk of mediastinal infections, consumption of blood products and length of intensive care unit (ICU) stay. Therefore, it is necessary to consider preventative measures to reduce the incidence of this complication (16). There is a controversy regarding use of desmopressin in prevention of postoperative bleeding. Hence, we aimed at assessing the preventive role of intranasal desmopressin in reducing blood loss and the need for administration of blood products after coronary artery bypass grafting (CABG) surgery under $\mathrm{CPB}$, in patients receiving antiplatelet drugs before surgery.

\section{Methods}

This study has been registered in the Iranian Registry of Clinical Trials (IRCT2013092114728N1). The present study was approved by the Ethics Committee of Tabriz University of Medical Sciences, and informed consent was obtained from the patients. In this prospective clinical trial, 40 patients admitted to Shahid Madani Heart Center were recruited. Patients were included if they were supposed to undergo CABG surgery with $\mathrm{CPB}$, aged over 18 years, and were on antiplatelet therapy (aspirin $80 \mathrm{mg}$ daily or clopidogrel $75 \mathrm{mg}$ daily) for a week before surgery. Exclusion criteria included reoperation heart surgery (other than surgery to control bleeding), history of coagulopathy, anticoagulant medication before surgery, patient disagreement, sensitivity to desmopressin, and kidney or liver diseases. Patients were divided into two groups receiving either desmopressin (case group, 20 patients) or normal saline (control group, 20 patients). All studied patients underwent CABG surgery with CPB and received lorazepam (1 mg), morphine $(0.1 \mathrm{mg} / \mathrm{kg} \mathrm{IM})$, and promethazine $(0.5 \mathrm{mg} / \mathrm{kg} \mathrm{IM})$ for premedication 30 minutes before surgery. After induction of general anesthesia, bleeding time (BT) was measured. After reversing heparin effect by protamine, case and control groups received desmopressin nasal spray (two puffs, $0.3 \mu \mathrm{g} / \mathrm{kg}$ ) and normal saline spray (two puffs) into the nose in control group were given. Then the patients were transferred to the ICU.

In the ICU, blood samples were taken from patients to assess prothrombin time (PT), partial thromboplastin time (PTT), international normalized ratio (INR), platelet count, activated clotting time (ACT), and after an hour of admission BT was re-measured. After 6 hours, either desmopressin nasal spray or saline was re-administered to the groups; in total patients received four puffs of desmopressin or normal saline. Patient vital signs, blood loss, administration of blood products, prescription drugs to improve the coagulation status, serum and whole intake and output of patients, need for a second surgery to control the bleeding, remaining sternum open, mortality due to 
bleeding, duration of ICU stay and mechanical ventilation were recorded.

Data were presented as mean \pm standard deviation (SD), or frequency (percentage). Statistical analysis was performed with SPSS 17 (SPSS, Chicago, Illinois) using independent Ttest for quantitative variables and chi-square or Fisher's exact test for qualitative variables. A P value $<0.05$ was considered statistically significant.

\section{Results}

Forty patients (20 patients in each group) completed the study. The mean age of all studied patients was $60.82 \pm 1.4$ years (range: 38-75). Duration of ICU stay in the case group was $4 \pm 0.4$ and in control group was $4 \pm 1$ $(P=0.05)$. Amount of heparin received during surgery was $240 \pm 12.24$ units in the case group and $233.3 \pm 12.01$ units in the control group $(P=0.9)$. Furthermore, bleeding volume after surgery was $619.09 \pm 149.03 \mathrm{cc}$ in the case group and $778.66 \pm 179.3 \mathrm{cc}$ in the control group $(P=0.57)$. The results of the study parameters are listed in Table 1.

\section{Discussion}

According to the increasing number and extent of heart surgery, most blood products are used in cardiac surgery wards. Until a few years ago, approximately $25 \%$ of allogeneic blood products were used in cardiac surgery. The use of CPB in cardiac surgery, amount of heparin used to prevent clotting in the CPB circuit, extent of heart surgery and performing heart surgery for the second, third and even fourth time all lead to hemostasis and coagulation disorders and increased bleeding during and after surgery. Postoperative bleeding is a complication that increases morbidity and mortality and is associated with various factors such as reduced heparin neutralization, thrombocytopenia and platelet function disorder, fibrinolysis, and coagulation factors dysfunction (17).
CPB temperature is among the factors that associate with bleeding and clotting disorders after cardiac surgery. Hypothermia has proven effects on the coagulation system; hypothermia in the range of commonly used during CPB (22$25^{\circ} \mathrm{C}$ ) causes reversible impaired platelet function and inhibition of activated coagulation factors $(18,19)$. Some believe that CPB performed in normothermic conditions results in improved coagulation factors performance and homeostasis maintenance, hence reduced postoperative bleeding. In the present study, the mean body temperature of patients during and after the operation was similar in the case and control groups. In the present study, patients receiving either desmopressin or saline were comparable in terms of the use of blood products, and blood coagulation parameters (e.g., BT, PT, PTT, INR, and platelet count).

In our study, we found no difference in total amount of postoperative bleeding in patients receiving either desmopressin or saline. Likewise, Temeck et al. (20) and Brown and colleagues (21) failed to detect any difference in bleeding between groups receiving desmopressin or placebo within the first 24 hours after cardiac surgery. Furthermore, Marquez and coworkers concluded that routine administration of desmopressin infusion vs. single dose in contrast to a single dose had no priority in reducing bleeding after CABG surgery (22). Nonetheless, Salzman and colleagues (23), and Dilthey et al. (24) reported that desmopressin reduced the amount of bleeding during and after surgery.

Limited side effects of desmopressin are indicated in several studies including drowsiness, headache, nausea, vomiting, weight gain, mild increase in blood pressure, fluid retention, nose bleeding, and decreased blood sodium. The latter problem is important as it can be associated with seizures in severe cases. In our study, we found no difference between two studied groups with regard to 


\begin{tabular}{|c|c|c|c|}
\hline & Case group & Control group & $P$ value \\
\hline Sex (Male:Female) & $12: 8$ & $16: 4$ & 0.15 \\
\hline Age (year) & $61.6 \pm 2.13$ & $60.05 \pm 1.84$ & 0.58 \\
\hline Weight (kg) & $74.7 \pm 2.62$ & $73.9 \pm 1.52$ & 0.79 \\
\hline Height $(\mathrm{cm})$ & $165.65 \pm 2.51$ & $165.85 \pm 1.91$ & 0.95 \\
\hline \multicolumn{4}{|l|}{ Anti-platelet agent } \\
\hline Aspirin & $18(90)$ & $20(100)$ & 0.24 \\
\hline Aspirin + clopidogrel & $2(10)$ & $0(0)$ & \\
\hline \multicolumn{4}{|l|}{ Time to drug discontinuation } \\
\hline To operation day & $3(15)$ & $3(15)$ & \\
\hline To one day before operation & $15(75)$ & $11(55)$ & 0.4 \\
\hline To two day before operation & $2(10)$ & $5(25)$ & \\
\hline To three day before operation & $0(0)$ & $1(5)$ & \\
\hline Operation time $(\mathrm{h})$ & $5.88 \pm 0.18$ & $6.2 \pm 0.2$ & 0.22 \\
\hline Pump time & $104.4 \pm 5.91$ & $107 \pm 3.47$ & 0.65 \\
\hline Aortic cross clamp time & $66.55 \pm 4.25$ & $59.2 \pm 4.21$ & 0.28 \\
\hline \multicolumn{4}{|l|}{ Number of coronary grafts } \\
\hline 1 & $1(5)$ & $0(0)$ & \\
\hline 2 & $5(25)$ & $4(20)$ & 0.29 \\
\hline 3 & $12(60)$ & $16(80)$ & \\
\hline 4 & $2(10)$ & $0(0)$ & \\
\hline Positive LIMA graft & $17(85)$ & $20(100)$ & 0.11 \\
\hline Heparin used in operation (unit) & $240 \pm 12.24$ & $233.3 \pm 12.01$ & 0.9 \\
\hline Protamine used for heparin reverse (mg) & $367.5 \pm 23.58$ & $370 \pm 15.27$ & 0.46 \\
\hline Duration of mechanical ventilation (h) & $32.5 \pm 4.94$ & $16.16 \pm 6.3$ & 0.13 \\
\hline ICU stay (days) & $4 \pm 0.4$ & $4 \pm 1$ & 0.05 \\
\hline Duration of aortic cross clamp (min) & $66.55 \pm 4.25$ & $59.2 \pm 4.21$ & 0.28 \\
\hline Sternum kept open after surgery & $4(20)$ & $3(15)$ & 0.5 \\
\hline Duration of postoperative sternum open (h) & $19.5 \pm 4.55$ & $14 \pm 2$ & 0.37 \\
\hline Reoperation due to bleeding & $3(15)$ & $1(5)$ & 0.3 \\
\hline Total amount of postoperative bleeding (cc) & $619.09 \pm 149.03$ & $778.66 \pm 179.3$ & 0.57 \\
\hline Urine output $24 \mathrm{~h}(\mathrm{cc})$ & $3681.82 \pm 174.1$ & $3463.3 \pm 241.2$ & 0.85 \\
\hline Total intake $24 \mathrm{~h}(\mathrm{cc})$ & $3875 \pm 361.7$ & $4002.5 \pm 330.8$ & 0.79 \\
\hline Total output $24 \mathrm{~h}(\mathrm{cc})$ & $4394.5 \pm 254.8$ & $4235.3 \pm 350.7$ & 0.73 \\
\hline Platelet concentrates used (cc) & $410.5 \pm 112.1$ & $414.2 \pm 125.7$ & 0.98 \\
\hline Platelet used (cc) & $12.5 \pm 10.01$ & $17.5 \pm 10.23$ & 0.81 \\
\hline Fresh frozen plasma used (cc) & $382.5 \pm 87.8$ & $335 \pm 103.4$ & 0.72 \\
\hline Systolic blood pressure (mmHg) & $115.5 \pm 3.73$ & $118.3 \pm 2.13$ & 0.34 \\
\hline Diastolic blood pressure ( $\mathrm{mmHg}$ ) & $63.5 \pm 2.71$ & $63.5 \pm 2.08$ & 0.81 \\
\hline Heart rate & $83.8 \pm 2.79$ & $90.39 \pm 2.54$ & 0.12 \\
\hline Temperature (oC) & $36.94 \pm 0.1$ & $36.8 \pm 0.09$ & 0.34 \\
\hline Primary BT (min) & $3.31 \pm 0.41$ & $3.94 \pm 0.44$ & 0.52 \\
\hline Secondary BT (min) & $4.91 \pm 1.93$ & $3.06 \pm 0.44$ & 0.32 \\
\hline PT (s) & $22.34 \pm 4.29$ & $15.05 \pm 0.3$ & 0.14 \\
\hline PTT (s) & $34.68 \pm 2.92$ & $31.18 \pm 2.57$ & 0.15 \\
\hline INR & $1.3 \pm 0.05$ & $1.27 \pm 0.04$ & 0.72 \\
\hline Platelet & $150.35 \pm 11.2$ & $166.5 \pm 15.71$ & 0.32 \\
\hline Serum sodium (mEq/L) & $139.23 \pm 7.18$ & $143 \pm 1.04$ & 0.08 \\
\hline Serum potassium (mEq/L) & $4.31 \pm 0.13$ & $4.37 \pm 0.11$ & 0.75 \\
\hline
\end{tabular}

Table 1: Demographic, clinical and laboratory characteristics between two studied groups LIMA: left internal mammary artery; ICU: intensive care unit; BT; bleeding time; PT: prothrombin time; PTT: partial thromboplastin time; INR: international normalized ratio. 
desmopressin side effects such as alteration in systolic and diastolic blood pressure of patients, and fluid retention (indicated by $24 \mathrm{~h}$ urinary output).
In conclusion, desmopressin has no significant effect on reducing the amount of bleeding after cardiac surgery in patients receiving anti-platelet agents.

\section{References}

1. Miller RD, Fleisher LA, Johns RA, Savarese JJ, Wiener-Kronish JP, Young WL. Miller's Anesthesia. Philadelphia: Churchill Livingstone; 2005.

2. Despotis GJ, Goodnough LT. Management approaches to platelet-related microvascular bleeding in cardiothoracic surgery. Ann Thorac Surg. 2000;70(2 Suppl):S20-S32.

3. Horrow JC, Van Riper DF, Strong MD, Brodsky I, Parmet JL. Hemostatic effects of tranexamic acid and desmopressin during cardiac surgery. Circulation. 1991;84(5):2063-70.

4. Lethagen S, Rugarn P, Bergqvist D. Blood loss and safety with desmopressin or placebo during aorto-iliac graft surgery. Eur J Vasc Surg. 1991;5(2):173-8.

5. Pleym H, Wahba A, Videm V, Asberg A, Lydersen S, Bjella L, Dale O, Stenseth R. Increased fibrinolysis and platelet activation in elderly patients undergoing coronary bypass surgery. Anesth Analg. 2006;102(3):660-7.

6. Harker LA, Malpass TW, Branson HE, Slichter S. Mechanism of abnormal bleeding in patients undergoing cardiopulmonary bypass: acquired transient platelet dysfunction associated with selective alpha-granule release. Blood. 1980;56(5):824-34.

7. Parolari A, Guarnieri D, Alamanni F, Toscano T, Tantalo V, Gherli T, Colli S, Foieni F, Franzè V, Stanghellini M, Gianotti GA, Biglioli P, Tremoli E. Platelet function and anesthetics in cardiac surgery: an in vitro and ex vivo study. Anesth Analg. 1999;89(1):26-31.

8. Shiffrin JS, Glass DD. Pro: desmopressin is of value in the treatment of post-cardiopulmonary bypass bleeding. J Cardiothorac Vasc Anesth. 1991;5(3):285-9.

9. Mannucci PM. Desmopressin (DDAVP) in the treatment of bleeding disorders: the first 20 years. Blood. 1997;90(7):2515-21.

10. Andersson T, Solem JO, Tengborn L, Vinge E. Effects of desmopressin acetate on platelet aggregation, von Willebrand factor, and blood loss after cardiac surgery with extracorporeal circulation. Circulation. 1990;81(3):872-8.

11. Despotis GJ, Levine V, Saleem R, Spitznagel E, Joist JH. Use of point-of-care test in identification of patients who can benefit from desmopressin during cardiac surgery: a randomised controlled trial. Lancet. 1999;354(9173):106-10.

12. Raja SG, Shahbaz Y. Desmopressin for haemostasis in cardiac surgery: when to use? Ann Card Anaesth. 2006;9(2):102-7.

13. Salmenperä $M$, Kuitunen $A$, Hynynen $M$, Heinonen J. Hemodynamic responses to desmopressin acetate after CABG: a double-blind trial. J Cardiothorac Vasc Anesth. 1991;5(2):146-9.

14. Weber CF, Dietrich W, Spannagl M, Hofstetter C, Jámbor C. A point-of-care assessment of the effects of desmopressin on impaired platelet function using multiple electrode whole-blood aggregometry in patients after cardiac surgery. Anesth Analg. 2010;110(3):702-7.

15. Weinstein M, Ware JA, Troll J, Salzman E. Changes in von Willebrand factor during cardiac surgery: effect of desmopressin acetate. Blood. 1988;71(6):1648-55.

16. Despotis GJ, Hogue Jr CW. Pathophysiology, prevention, and treatment of bleeding after cardiac surgery: a primer for cardiologists and an update for the cardiothoracic team. Am J Cardiol. 1999;83(4):15-30.

17. Milas BL, Jobes DR, Gorman RC. Management of bleeding and coagulopathy after heart surgery. Semin Thorac Cardiovasc Surg. 2000;12(4):326-36. 
18. Cook DJ. Changing temperature management for cardiopulmonary bypass. Anesth Analg. 1999;88(6):1254-71.

19. Valeri CR, Feingold H, Cassidy G, Ragno G, Khuri S, Altschule MD. Hypothermia-induced reversible platelet dysfunction. Ann Surg. 1987;205(2):175-81.

20. Temeck BK, Bachenheimer LC, Katz NM, Coughlin SS, Wallace RB. Desmopressin acetate in cardiac surgery: a double-blind, randomized study. South Med J. 1994;87(6):611-5.

21. Brown MR, Swygert TH, Whitten CW, Hebeler R. Desmopressin acetate following cardiopulmonary bypass: Evaluation of coagulation parameters. J Cardiothorac Anesth. 1989;3(6):726-9.

22. Marquez J, Koehler S, Strelec SR, Benckart DH, Spero JA, Cottington EM, Torpey DJ Jr. Repeated dose administration of desmopressin acetate in uncomplicated cardiac surgery: a prospective, blinded, randomized study. J Cardiothorac Vasc Anesth. 1992;6(6):674-6.

23. Salzman EW, Weinstein MJ, Weintraub RM, Ware JA, Thurer RL, Robertson L, Donovan A, Gaffney T, Bertele V, Troll J, et al. Treatment with desmopressin acetate to reduce blood loss after cardiac surgery. A double-blind randomized trial. N Engl J Med. 1986;314(22):1402-6.

24. Dilthey G, Dietrich W, Spannagl M, Richter JA. Influence of desmopressin acetate (DDAVP) on homologous blood requirement in cardiac surgical patients pretreated with platelet-inhibiting drugs. J Cardiothorac Vasc Anesth. 1993;7(4):425-30. 